\title{
Novel Glycosylation of Aromatic Amines Through 1, 2-Anhydrosugars
}

Ram Naresh Yadav ${ }^{1,2}$ and Bimal K Banik ${ }^{1,3^{*}}$

${ }^{1}$ Department of Chemistry, The University of Texas-Pan American, 1201 West University Drive, Edinburg, TX 78539, USA

${ }^{2}$ Department of Chemistry, Faculty of Engineering and Technology, Veer Bahadur Singh Purvanchal University, Jaunpur-222003, Uttar Pradesh, India

${ }^{3}$ Community Health Systems of South Texas, Edinburg, Texas 78539, USA

*Corresponding author: Bimal K Banik, Vice President, Community Health Systems of South Texas, Edinburg, Texas 78539, USA, Tel: 09566658741; E-mail: bimalbanik10@gmail.com

Rec date: April 18, 2018; Acc date: April 30, 2018; Pub date: May 08, 2018

Copyright: (c) 2018 Yadav RN, et al. This is an open-access article distributed under the terms of the Creative Commons Attribution License, which permits unrestricted use, distribution, and reproduction in any medium, provided the original author and source are credited.

\begin{abstract}
A new and novel bismuth nitrate and indium bromide-catalyzed glycosylation of aromatic amines with glycal epoxides is described in moderate yield. Despite the poor nucleophilicity of the aromatic amines, the success of this reaction is noteworthy.
\end{abstract}

Keywords: Glycosylation; Amine; Epoxide; Catalyst

\section{Introduction}

Acid-catalyzed glycosylation of alcohols and thiols is an attractive field of research. The nucleophilicity of alcohols and thiols is high enough to react with an anomeric center of a sugar system that has an alkene, hydroxy or halogen group [1-12]. It is necessary to activate the reactants by acidic catalysts. However, glycosylation of aromatic amines with the above mentioned sugar derivatives are extremely difficult. Aromatic amines are much less nucleophilic compared to alcohols and thiols. In this communication, a simple bismuth nitrate and indium bromide-catalyzed reactions of 1,2-anhydrosugars and diverse aromatic amines is described [13-39]. The success, although not excellent, deserve special attention as synthesis of these types of molecules is not known. Moreover, the method for aromatic glycosylation is not investigated.

\section{Results and Discussion}

Glycosylation of $\beta$-lactam alcohols and other alcohols were studied by our group [1-12]. This was performed with iodine-catalyzed and indium metal-catalyzed reactions of alcohols and glycal or bromo sugar derivatives. The success of this reaction was excellent. In parallel studies, bismuth nitrate and indium bromide were also investigated as catalysts for the glycosylation reaction of aromatic amines. Aromatic primary amines are widely distributed in nature. Perhaps, aromatic primary amines are the most widely studied functional groups in chemistry. However, carbohydrates bound to aromatic amine through its anomeric center and the nitrogen of the amine is difficult to obtain. To overcome the shortcomings, the reaction of aromatic amines with sugar epoxide was chosen.

At the beginning of this approach protected sugar epoxide 2 was prepared from glycal 1 by DMDO-catalyzed oxidation reaction (Scheme 1). The epoxide 2 on reaction with different aromatic primary amines in the presence of bismuth nitrate and indium bromide afforded the sugar-linked $\mathrm{NH}$-aryl systems 3 ( $\alpha$-isomer) and $4(\beta$ isomer) in moderate yield. The ratios of the $\beta$-isomers were much higher than the ratios of the $\alpha$-isomers irrespective of the nature of the solvents and catalysts used in these reactions (Scheme 2 and Table 1). In general, it was found that glycal epoxide was consumed within $2-6 \mathrm{~h}$.

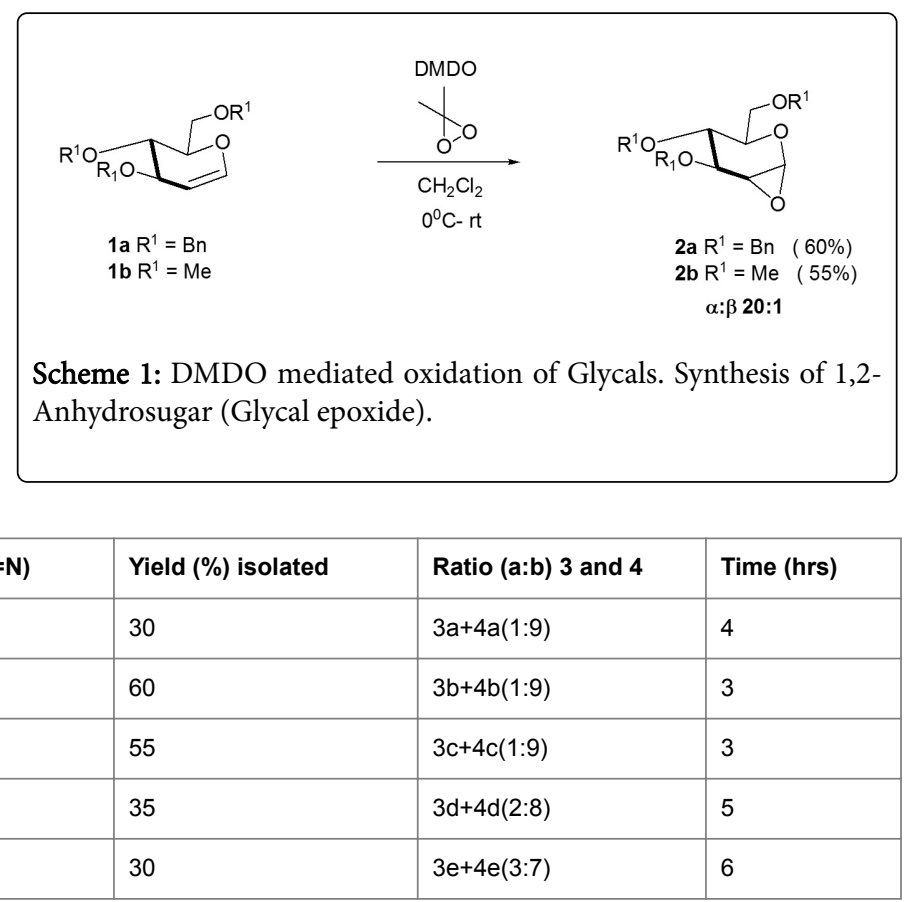


Citation: Yadav RN, Banik BK (2018) Novel Glycosylation of Aromatic Amines Through 1, 2-Anhydrosugars. Mod Chem Appl 6: 259. doi:

Page 2 of 3

\begin{tabular}{|c|c|c|c|c|c|c|c|}
\hline & \multirow[t]{5}{*}{$1 a R^{1}=B n$} & \multirow[t]{5}{*}{$\operatorname{lnBr}_{3}$} & \multirow[t]{5}{*}{$\mathrm{CH}_{2} \mathrm{Cl}_{2}$} & Aniline & 60 & $3 a+4 a(1: 9)$ & 3 \\
\hline & & & & p-Anisidine & 70 & $3 a+4 a(1: 9)$ & 2 \\
\hline & & & & p-Toludine & 65 & $3 a+4 a(1: 9)$ & 2 \\
\hline & & & & 9-AP & 45 & $3 a+4 a(2: 8)$ & 4 \\
\hline & & & & $6-A C$ & 40 & $3 a+4 a(3: 7)$ & 5 \\
\hline \multirow[t]{10}{*}{2} & \multirow[t]{5}{*}{$1 \mathrm{~b} \mathrm{R} \mathrm{R}^{1}=\mathrm{Me}$} & \multirow[t]{5}{*}{$\mathrm{Bi}\left(\mathrm{NO}_{3}\right)_{3} .5 \mathrm{H}_{2} \mathrm{O}$} & \multirow[t]{5}{*}{ THF } & Aniline & 45 & $5 a+6 a(1: 9)$ & 3 \\
\hline & & & & p-Anisidine & 65 & $5 b+6 b(1: 9)$ & 2 \\
\hline & & & & p-Toludine & 50 & $5 c+6 c(1: 9)$ & 2 \\
\hline & & & & 9-AP & 40 & $5 d+6 d(2: 8)$ & 4 \\
\hline & & & & 6-AC & 30 & $5 e+6 e(3: 7)$ & 5 \\
\hline & \multirow[t]{5}{*}{$1 b R^{1}=M e$} & \multirow[t]{5}{*}{$\operatorname{lnBr}_{3}$} & \multirow[t]{5}{*}{$\mathrm{CH}_{2} \mathrm{Cl}_{2}$} & Aniline & 50 & $5 a+6 a(1: 9)$ & 3 \\
\hline & & & & p-Anisidine & 60 & $5 b+6 b(1: 9)$ & 2 \\
\hline & & & & p-Toludine & 55 & $5 c+6 c(1: 9)$ & 2 \\
\hline & & & & 9-AP & 35 & $5 d+6 d(2: 8)$ & 4 \\
\hline & & & & $6-A C$ & 50 & $5 e+6 e(3: 7)$ & 5 \\
\hline
\end{tabular}

Table 1: Reaction condition and products ratios of the nucleophilic ring opening of glucal epoxide. 9-AP (9-Aminophenantherene); 6-AC (6Aminochrysene).

The reaction proceeded with monocyclic to tetracyclic primary aromatic amines. Polyaromatic compounds, like 9aminophenanthrene and 6-aminochrysene are extremely weak nucleophiles and sterically hindered. It was very interesting to note that these polyaromatic primary amines reacted with sugar epoxide in the presence of bismuth nitrate and indium bromide. To our knowledge carbohydrates directly linked to the amino group of aromatic compounds is not known. In our earlier studies, polyaromatic amino compounds were used as anticancer agents [40-43]. However, structurally the compound described herein is totally different than our previous compounds.

$$
\begin{aligned}
& \mathrm{R}^{1} \mathrm{O}_{\mathrm{R}_{1}} \mathrm{O} \cdot \mathrm{C}_{\mathrm{O}}^{\mathrm{O} \mathrm{R}^{1}} \\
& \begin{array}{ll}
\text { 2a R } R^{1}=\operatorname{Bn} & (60 \%) \\
\text { 2b R R }^{1}=\operatorname{Me} \quad(555 \%)
\end{array}
\end{aligned}
$$

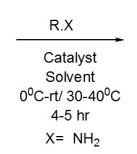

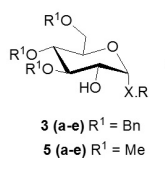

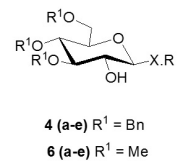

Scheme 2: Stereo selective ring opening of glucal epoxide with $\mathrm{N}$ nucleophile. A facile high stereo selective synthesis of $\mathrm{N}$ glycoside.

The formation of $\beta$-isomer is explained by the nucleophilic attack of the aromatic amino group from the opposite face of the sugar epoxide. This type of attack is favored because of the steric hindrance imposed by the aromatic ring. Since cleavage of an epoxide ring is possible from both sides of this functional group, formation of minor amounts of $\alpha$ isomer is also observed.

\section{Conclusion}

A method of aromatic amino glycosylation reaction with sugar epoxide in the presence of bismuth nitrate and indium bromide is achieved in moderate yield. This reaction is totally unknown and therefore, there is an enormous possibility to study this reaction. For example, identification of other catalysts, temperature, protective group in sugars and alteration of the nucleophilicity of the aromatic amines can be undertaken. Nevertheless, the present study opens up a new method for the preparation of several unknown molecules. On the basis of the biological activities of related molecules, we expect to publish the full paper in this field in the future.

\section{Acknowledgements}

Bimal Krishna Banik is grateful to NIH, NCI, Kleberg Foundation, University of Texas M. D. Anderson Cancer Center, University of Texas-Pan American, University of Texas Health Science Center at San Antonio and Community Health System of South Texas for providing the necessary funding and laboratory space.

\section{References}

1. Banik BK, Manhas MS, Bose AK (1997) Enantiopure $\alpha$-hydroxy- $\beta$ lactams via stereoselective glycosylation. Tetrahedron Lett 38: 5077-5080.

2. Banik BK, Zegrocka O, Manhas MS, Bose AK (1997) Enantiomerically pure $\beta$-lactams with the thienamycin side chain via glycosylation. Heterocycles 46: 173-176.

3. Banik BK, Manhas MS, Bose AK (1994) Stereospecific glycosylation via Ferrier rearrangement for optical resolution. J Org Chem 59: 4714-4716.

4. Banik BK, Zegrocka O, Manhas MS (2009) A facile iodine-catalyzed glycosylation: enantiomerically pure $\beta$-lactams with the thienamycin side chain. Heterocycles 78: 2443-2454. 
5. Banik BK, Manhas MS (2012) Iodine-catalyzed stereospecific glycosylation of alcohols: enantiopure $\beta$-lactams. Tetrahedron 68: 10769-10779.

6. Banik BK, Mukhopadhyay C, Logan CR, Becker FF (2007) Optical Resolution of Dibenzo [a, g] fluorenol via Glycosylation. Synth Commun 37: 3895-3900.

7. Banik BK, Banik I, Becker FF (2010) Asymmetric synthesis of anticancer $\beta$-lactams via Staudinger reaction: Utilization of chiral ketene from carbohydrate. Eur J Med Chem 45: 846-848.

8. Banik BK, Samajdar S, Banik I (2001) Indium-mediated stereospecific glycosylation of alcohols. Heterocycles 55: 227-230.

9. Banik I, Samajdar S, Banik BK (2011) Stereospecific Chiral Resolution of Trans 2-Phenylcyclohexanol via Indium-Induced Glycosylation. Heterocycl Lett, pp: 47-48.

10. Samajdar S, Banik I, Banik BK (2011) Indium-Induced Highly Stereoselective Thioglycosylation of Peracetylated Bromoglucose. Heterocycl Lett, pp: 41-42.

11. Banik BK, Samajdar S, Becker FF (2010) Asymmetric synthesis of anticancer $\beta$-lactams via Staudinger reaction. Mol Med Rep 3: 319-321.

12. Chandra S, Yadav RN, Paniagua A, Banik BK (2016) Indium saltscatalyzed $\mathrm{O}$ and S-glycosylation of bromo sugar with benzyl glycolate: An unprecedented hydrogenolysis. Tetrahedron Lett 57: 1425-1429.

13. Lerma J, Banik BK (2011) Synthesis of Glucose Peracetate via Bismuth Nitrate-Induced Reaction. Heterocycl Lett, pp: 35-36.

14. Banik BK, Adler D, Nguyen P (2003) A New Bismuth Nitrate-induced Stereospecific Glycosylation of Alcohols (Heterocycles 30 th in Anniversary Issue). Heterocycles 61: 101-104.

15. Alvarez D, Banik BK (2011) Stereospecific synthesis of glycosyl chloride using a combination of bismuth nitrate and bismuth chloride. Heterocycl Lett, pp: 37-39.

16. Samajdar S, Becker FF, Banik BK (2000) Surface-Mediated Highly Efficient Regioselective Nitration of Aromatic Compounds by Bismuth Nitrate. Tetrahedron Lett 41: 8017-8020.

17. Samajdar S, Becker FF, Banik BK (2001) Montmorillonite Impregnated With Bismuth Nitrate: A Versatile Reagent for the Synthesis of Nitro Compounds of Biological Significance. Arkivoc 2: 27-33.

18. Bandyopadhyay D, Mukherjee S, Granados JC, Short JD, Banik BK (2012) Ultrasound-assisted bismuth nitrate-induced green synthesis of novel pyrrole derivatives and their biological evaluation as anticancer agents. Eur J Med Chem 50: 209-215.

19. Bandyopadhyay D, Sanchez JL, Guerrero AM, Chang FM, Granados JC, et al. (2015) Design, synthesis and biological evaluation of novel pyrenyl derivatives as anticancer agents. Eur J Med Chem 89: 851-862.

20. Bandyopadhyay D, Granados JC, Short JD, Banik BK (2012) Polycyclic aromatic compounds as anticancer agents: evaluation of synthesis and in vitro cytotoxicity. Oncol Lett 3: 45-49.

21. Canales L, Bandyopadhyay D, Banik BK (2011) Bismuth nitrate pentahydrate-induced novel nitration of eugenol. Org Med Chem Lett 1: $1-9$.

22. Bose A, Sanjoto WP, Villarreal S, Aguilar H, Banik BK (2007) Novel nitration of estrone by metal nitrates. Tetrahedron Lett 48: 3943-3946.

23. Bandyopadhyay D, Rivera G, Sanchez JL, Rivera J, Granados JC, et al. (2014) Bismuth nitrate-induced novel nitration of estradiol: An entry to new anticancer agents. Eur J Med Chem 82: 574-583.

24. Iglesias L, Aguilar C, Bandyopadhyay D, Banik BK (2010) Bismuth Nitrate-Catalyzed Synthesis of Bis Indoloylmethane Under Solventless Conditions. Synth Commun 40: 3678-3682.

25. Rivera S, Iglesias L, Bandyopadhyay D, Banik BK (2011) Microwaveinduced bismuth nitrate-catalyzed electrophilic substitution of indole with keto ester under slovent-free conditions. Heterocycl Lett, pp: 73-74.
26. Rivera S, Bandyopadhyay D, Banik BK (2011) Microwave-induced bismuth nitrate-catalyzed electrophilic substitution of 7-aza indole with activated carbonyl compound under solvent-free conditions. Heterocycl Lett 1: 43-46.

27. Srivastava N, Dasgupta SK, Banik BK (2003) A remarkable bismuth nitrate-catalyzed protection of carbonyl compounds. Tetrahedron Lett 44 : 1191-1193.

28. Samajdar S, Basu MK, Becker FF, Banik BK (2002) Bismuth nitratemediated deprotection of oximes. Synth Commun 32: 1917-1921.

29. Bandyopadhyay D, Banik BK (2011) Microwave-Induced Bismuth Nitrate-Catalyzed Expeditious Enamination of $\beta$-Dicarbonyl Compounds Under Solvent-Free Conditions. Heterocycl Lett, pp: 17-21.

30. Bandyopadhyay D, Banik BK (2012) Bismuth nitrate-induced microwave-assisted expeditious synthesis of vanillin from curcumin. Org Med Chem Lett 2: 15-19.

31. Bandyopadhyay D, Fonseca RS, Banik BK (2011) Microwave-induced bismuth nitrate-mediated selective hydrolysis of amide. Heterocycl Lett, pp: 75-77.

32. Banik BK, Cardona M (2006) Bismuth nitrate-catalyzed novel synthesis of pyrrole-substituted indolinones. Tetrahedron Lett 47: 7385-7387.

33. Rivera S, Bandyopadhyay D, Banik BK (2009) Facile synthesis of Nsubstituted pyrroles via microwave-induced bismuth nitrate-catalyzed reaction. Tetrahedron Lett 50: 5445-5448.

34. Bandyopadhyay D, Mukherjee S, Banik BK (2010) An expeditious synthesis of $\mathrm{N}$-substituted pyrroles via microwave-induced iodinecatalyzed reactions under solventless conditions. Molecules 15: 2520-2525.

35. Shaikh A, Banik BK (2012) A Novel Asymmetric Synthesis of 3-Pyrrole Substituted $\beta$-Lactams via Bismuth Nitrate-Catalyzed Reaction. Helv Chim Acta 95: 839-844.

36. Srivastava N, Banik BK (2003) Bismuth nitrate-catalyzed versatile Michael reactions. J Org Chem 68: 2109-2114.

37. Bandyopadhyay D, Cruz J, Banik BK (2012) Microwave-Induced Synthesis of 3-Pyrrole Substituted $\beta$-Lactams via Bismuth NitrateCatalyzed Reaction. Tetrahedron 68: 10686-10695.

38. Bandyopadhyay D, Maldonado S, Banik BK (2012) A microwave-assisted bismuth nitrate-catalyzed unique route toward 1, 4-dihydropyridines. Molecules 17: 2643-2662.

39. Banik BK, Reddy AT, Datta A, Mukhopadhyay C (2007) Microwaveinduced bismuth nitrate-catalyzed synthesis of dihydropyrimidones via Biginelli condensation under solventless conditions. Tetrahedron Lett 48: 7392-7394.

40. Becker FF, Banik BK (1998) Polycyclic aromatic compounds as anticancer agents: synthesis and biological evaluation of some chrysene derivatives. Bioorg Med Chem Lett 8: 2877-2880.

41. Banik BK, Becker FF (2001) Synthesis, electrophilic substitution and structure-activity relationship studies of polycyclic aromatic compounds towards the development of anticancer agents. Curr Med Chem 8: 1513-1532.

42. Banik BK, Becker FF (2001) Polycyclic aromatic compounds as anticancer agents: structure-activity relationships of chrysene and pyrene derivatives. Bioorg Med Chem 9: 593-605.

43. Becker FF, Mukhopadhyay C, Hackfeld L, Banik I, Banik BK (2000) Polycyclic aromatic compounds as anticancer agents: synthesis and biological evaluation of dibenzofluorene derivatives. Bioorg Med Chem 8: 2693-2699. 